\title{
Characteristics and Formation Mechanisms of Welding Defects in Underwater Friction Stir Welded Aluminum Alloy
}

\author{
Huijie Zhang • Huijie Liu
}

Received: 7 August 2012/Revised: 25 September 2012/ Accepted: 3 October 2012/Published online: 29 November 2012 (C) Springer Science+Business Media New York and ASM International 2012

\begin{abstract}
Underwater friction stir welding (FSW) has been demonstrated to be a promising method for strength improvement of heat-treatable aluminum alloy joints. However, when improper welding parameters are utilized, welding defects, such as voids can be produced in the joints, leading to dramatically deteriorated mechanical properties. Thus to obtain high-quality underwater joints, it is necessary to understand the variables that promote the formation of these defects. In this study, the characteristics of welding defects in underwater joints were examined, and the formation mechanisms of the defects were investigated by analyzing the material flow patterns during underwater FSW. The results indicated that welding defects can occur at both low- and high-rotation speeds (HRS). The defects formed at HRS can be divided into two types according to the welding speed. When a HRS and a low welding speed are chosen, the material beneath the tool shoulder tends to be extruded into the pin stirred zone (PSZ) after flowing back to the advancing side. This results in a turbulent flow condition, creating void defects in the PSZ. When a high welding speed is coupled with the HRS, a large amount of material from the thermo-mechanically affected zone is dragged into the pin hole, which causes the material of the
\end{abstract}

\section{H. Zhang $(\bowtie) \cdot$ H. Liu}

State Key Laboratory of Advanced Welding and Joining, Harbin Institute of Technology, Harbin 150001, People's Republic of China

e-mail: xfwineer@yahoo.cn

H. Liu

e-mail: liuhj@hit.edu.cn

\section{H. Zhang}

State Key Laboratory of Robotics, Shenyang Institute of Automation, Chinese Academy of Sciences, Shenyang 110016, People's Republic of China shoulder stirred zone to fill the pin hole in a downward flow direction. This leads to turbulent flow in PSZ, and creates voids or even groove defects in the as-welded joints.

Keywords Aluminum $\cdot$ Welding $\cdot$ Light microscopy

\section{Introduction}

Friction stir welding (FSW) is a novel joining technology presented by The Welding Institute at the beginning of the 1990s [1]. As the process occurs in the solid-state, FSW largely avoids the problems of solidification and liquation cracking, which are inherent in fusion welding. This attribute has led FSW to be successfully utilized to weld metals with low melting points such as aluminum and magnesium alloys [2-5].

During the FSW of heat-treatable aluminum alloys, the resulting thermal cycles tend to coarsen or dissolve the strengthening precipitates in the alloy, creating a softened region and lowering the mechanical properties of the joints [6-9]. Therefore, several researchers have applied external liquid cooling during the FSW process to improve the mechanical properties of the joints by controlling the thermal cycling. Benavides et al. [10] performed FSW of 2024 aluminum alloy using liquid nitrogen cooling to decrease the starting temperature of plates to be welded. Fratini et al. [11, 12] experimented with in-process heat treatment with water flowing on the top surface of the samples during FSW. To take full advantage of the heat absorption capacity of water, underwater FSW of 2219-T6 aluminum alloy was conducted by the present authors, during which the whole work piece was kept immersed in the water environment [13-15]. These investigations all demonstrated the feasibility of external liquid cooling to 
improve the performance of heat-treatable aluminum alloy joints.

During both normal and external-liquid-cooling FSW, if improper welding parameters are chosen, welding defects such as void or grooves, can form in the joints, which can dramatically deteriorate the mechanical properties [15-18]. Thus, understanding the characteristics and formation mechanisms of welding defects are of critical importance for obtaining high-quality FSW joints.

For normal FSW of aluminum alloys, a considerable amount of information is available on welding defects, and the defects are commonly considered to occur due to inadequate or excess heat input [19-22]. When less frictional heat is generated at the tool/work piece interface, the lower plasticity of material does not permit complete filling of the hole produced by the pin rotation, which consequently leads to defect formation [10, 16, 17, 19-21]. Conversely, when excess heat is generated by using improper parameters (e.g., higher rotation speeds), the formation mechanisms of defects are not quite clear. In the FSW of ADC12 aluminum alloy, it was found that voids were formed in the joint when the rotation speed was increased up to a certain value, and the size of the defect increased with increasing the welding speed [20]. The authors claimed that the defects formed at higher rotation speeds resulted from different temperatures between the upper part near the surface and the lower part, but they did not provide detailed explanation for this. In the investigation of Arbegast [21], when relatively high-rotation speeds (HRS) were utilized, the material directly under the shoulder was partially extruded into the stir zone (SZ) after flowing back to the advancing side (AS). The authors considered this as the reason for the occurrence of defects. Gaafer et al. [23] pointed out that the excess heat input induced by HRS could increase the fluidity of the metal and create turbulent flow at the weld zone, which may contribute to the formation of cavities; however, further investigation was not conducted to conclusively prove this point. These results imply that the formation mechanisms of the defects formed at HRS are still unresolved. Based on this uncertainty, the present research was conducted with focus placed on two aspects. One is to analyze the characteristics of defects formed in external-liquid-cooling FSW, with the intent to provide guidance for process optimization. The other aspect is clarification of the formation mechanisms of welding defects produced at HRS by studying material flow patterns of the underwater joints.

\section{Experimental Procedure}

The base material used for the experiment was a $7.5-\mathrm{mm}$ thick 2219-T6 aluminum alloy with the chemical composition
Table 1 Chemical compositions of 2219-T6 aluminum alloy (wt.\%)

\begin{tabular}{lllllllll}
\hline $\mathrm{Al}$ & $\mathrm{Cu}$ & $\mathrm{Mn}$ & $\mathrm{Fe}$ & $\mathrm{Ti}$ & $\mathrm{V}$ & $\mathrm{Zn}$ & $\mathrm{Si}$ & $\mathrm{Zr}$ \\
\hline Balance & 6.48 & 0.32 & 0.23 & 0.06 & 0.08 & 0.04 & 0.49 & 0.2 \\
\hline
\end{tabular}

shown in Table 1. The plate was machined into rectangular welding samples with dimension of $300 \mathrm{~mm}$ long by $100 \mathrm{~mm}$ wide. After cleaning with acetone, the samples were clamped to the backing plate in a vessel, and then room-temperature water was poured into the vessel to immerse the top surface of the samples. Underwater FSW experiments were conducted along the longitudinal direction (perpendicular to the rolling direction) of the welding samples.

The welding tool consisted of a 22.5-mm-diameter shoulder and a conical right-hand threaded pin with a length of $7.4 \mathrm{~mm}$ and median diameter of $7.4 \mathrm{~mm}$. W6Mo5Cr4V2 high-speed steel was used as the tool material. The tool tilt angle was $2.5^{\circ}$ during the FSW process. In the investigation of Kim et al. [20], it was demonstrated that the variation of axial load had little effect on the size of the defects formed at HRS. Therefore, the effect of axial load on weld formation was not investigated in this work; axial load was kept at a constant value of $4.6 \mathrm{kN}$. The rotation speed and the welding speed were varied between 600 and $1400 \mathrm{rpm}$, and 100 and $300 \mathrm{~mm} / \mathrm{min}$, respectively.

After welding, the joints were cross sectioned perpendicular to the welding direction for metallographic analyses. Cross sections were polished using diamond paste, etched with Keller's reagent and examined via light microscopy.

\section{Experimental Results}

\section{Characteristics of Underwater FSW Defects}

Figure 1 shows the evolutions of weld quality with rotation speed and welding speed. These results indicate that both LRS and HRS can yield welding defects in the joints; furthermore, the rotation speed range for defect-free joints is gradually narrowed as the welding speed is increased.

Figure 2 shows cross sections of the joints formed under different welding parameters. It should be noted that the retreating side (RS) is on the left, while the AS is on the right for each cross section in the figure; this convention is used throughout this manuscript.

In the low-rotation speed (LRS) range of 600-800 rpm, a groove defect is formed at the interface between the $\mathrm{SZ}$ and the thermo-mechanically affected zone (TMAZ) on the AS due to insufficient heat input (see Fig. 3a). For convenience, the defects formed at relatively LRS are referred to as LRS 


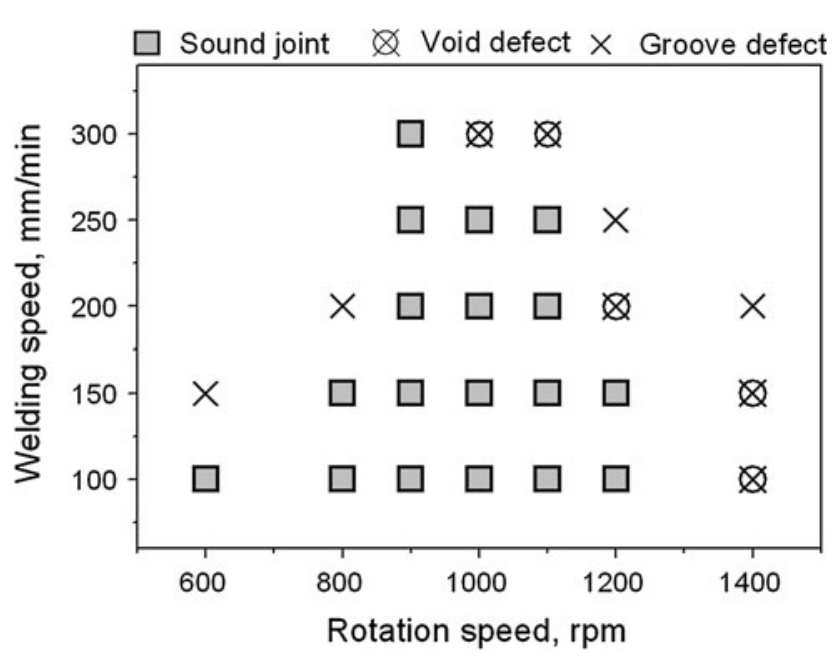

Fig. 1 Influence of process parameters on the quality of underwater joints defects. Increasing the rotation speed or decreasing the welding speed to certain values can remove the LRS defects.

The defects formed at relatively HRS (1000-1400 rpm) referred to as HRS defects, exhibit two features that are distinct from the LRS defect. First, the HRS defect tends to be formed at the inner part of SZ instead of SZ/TMAZ interface (see Figs. 2, 3). Second, the effect of welding parameters on the size of HRS defect is quite different from that of LRS defect. With increasing rotation speed, the size of the HRS defect does not decrease but rather increases. These two observations indicate that the formation mechanism of HRS defects may be different from that of LRS defects.

\section{Material Flow Patterns During Underwater FSW}

Many researchers have investigated the material flow patterns during FSW by analyzing the characteristics of

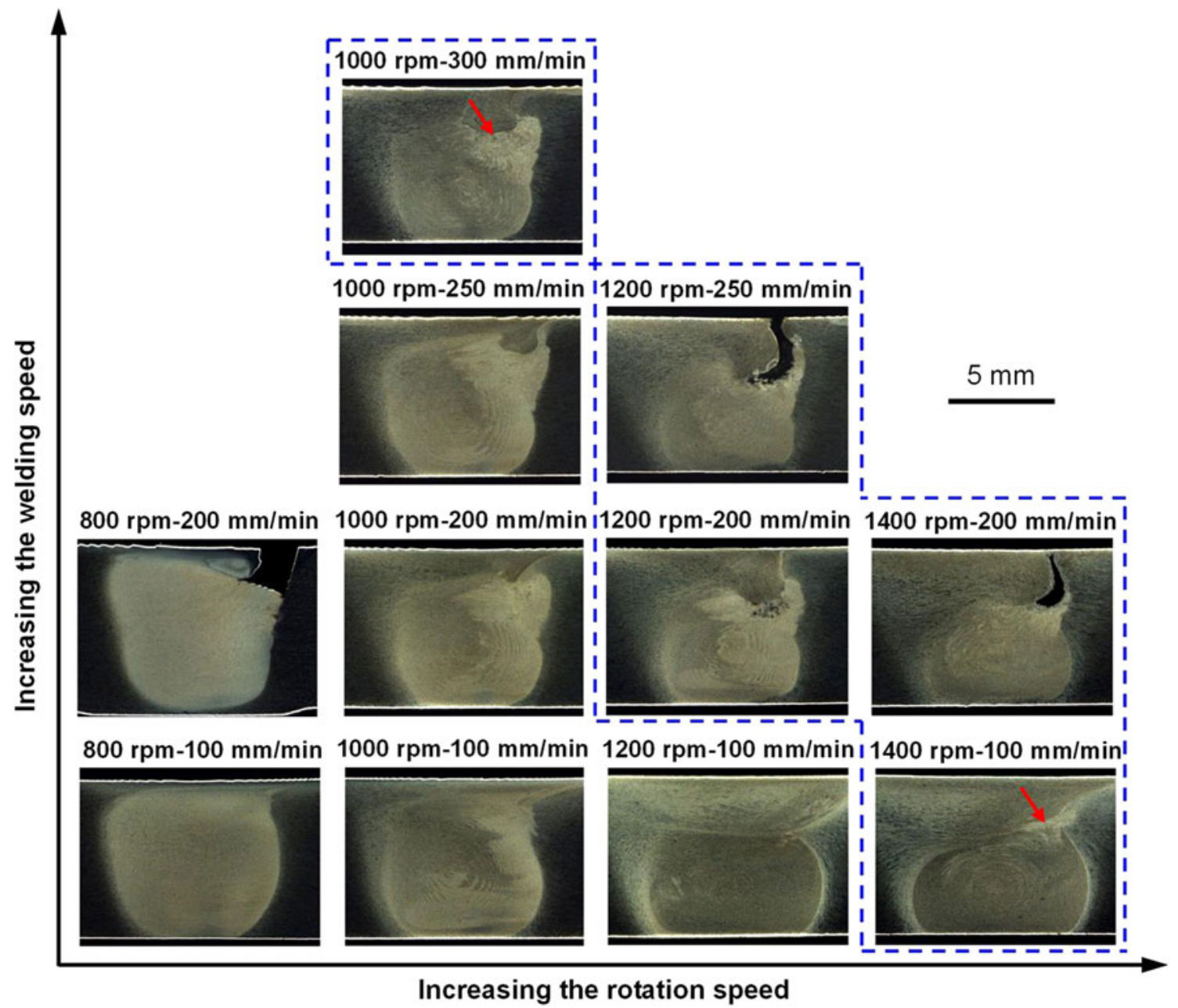

Fig. 2 Weld formation obtained at different process parameters. The welds with HRS defects are marked by dashed line, and the exact locations of very small defects are indicated by red arrow 
Fig. 3 High-magnification images of the welding defects formed under different process parameters: a $800 \mathrm{rpm}-$ $200 \mathrm{~mm} / \mathrm{min}$, b $1000 \mathrm{rpm}-$ $300 \mathrm{~mm} / \mathrm{min}$, c $1400 \mathrm{rpm}-$ $100 \mathrm{~mm} / \mathrm{min}$
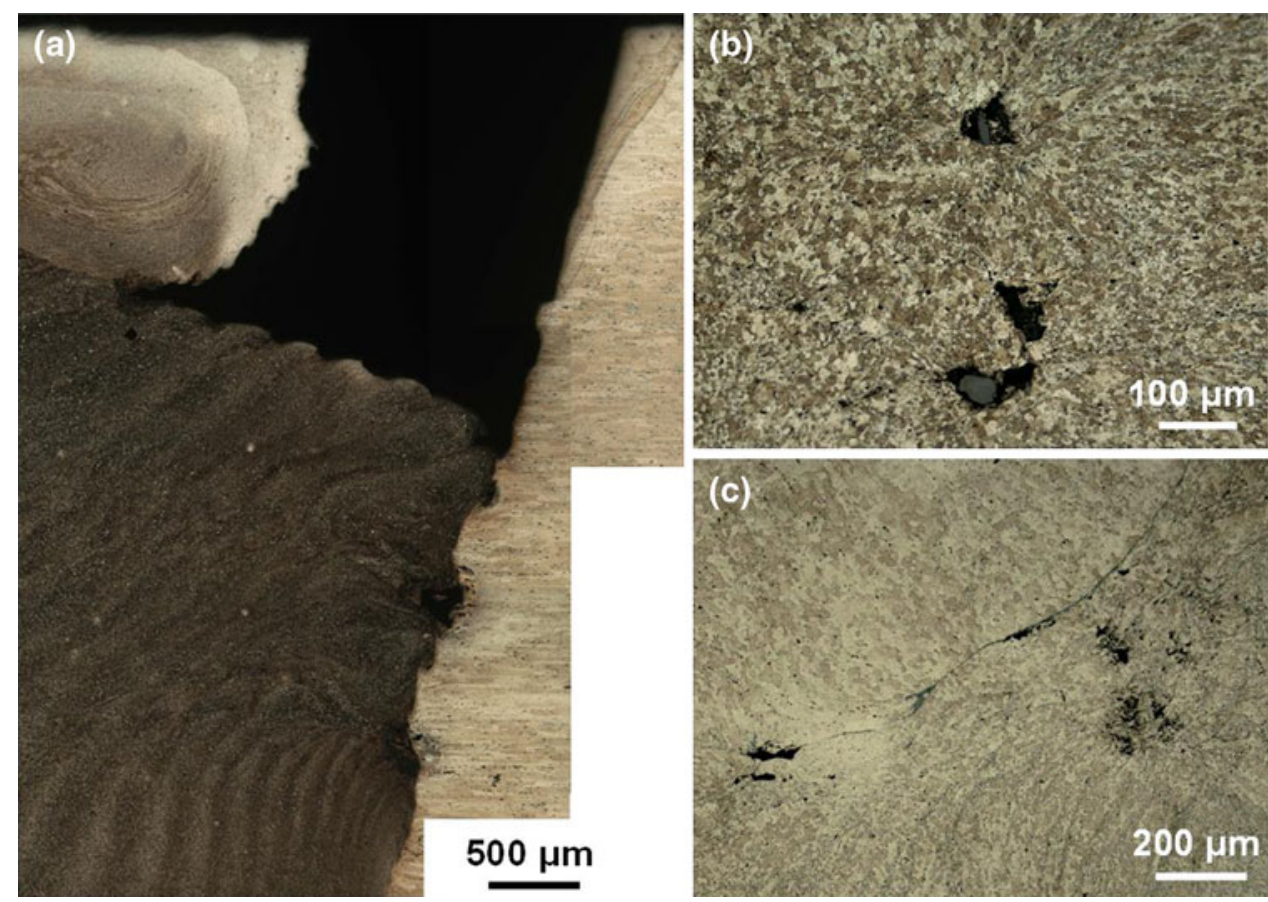

welding defects [24-27]. Inversely, in this study, the material flow patterns are utilized to explain the formation mechanisms of welding defects.

Figure 4(a) shows the cross section of a typical underwater joint, which was produced at a rotation speed of $1000 \mathrm{rpm}$ and a welding speed of $200 \mathrm{~mm} / \mathrm{min}$. Figure 4(b)-(d) shows the microstructures of deformed zones of the joint. The material directly stirred by welding tool is extruded around the RS and fills the hole at the rear of the tool. This part of material undergoes intense plastic deformation and forms a region composed of fine recrystallized grains, which is commonly referred to as the SZ. The upper part of SZ mainly experiences the stirring action of tool shoulder, while the lower part of SZ mainly experiences the stirring action of tool pin; hence, the SZ displays different fine grain structures between its upper and lower regions (see Fig. 4c, d). In this article, the upper region of SZ is referred to as the shoulder stirred zone (SSZ), and the lower region is referred to as the pin stirred zone (PSZ). The surrounding material constraining the SZ is deformed by passage of the tool and forms the TMAZ. Therefore, the deformed zones of the underwater joint are composed of three parts, i.e., SSZ, PSZ, and TMAZ. For each deformed zone, especially the SSZ and TMAZ, the flow direction of the elongated base material grains is actually a reflection of the material flow direction. The material flow patterns of the deformed zones can be deduced from Fig. 4(e) and are listed below.

I. A part of the SSZ material transferred from the RS to the AS flows into PSZ along the long axis direction of the grains of the TMAZ. In the statements below, this flow pattern is defined as "extruding reflux of SSZ material". Due to different microstructures and flow directions, the material that undergoes extruding reflux shows clear boundaries toward TMAZ material and the remaining SSZ material. The extent of extruding reflux is determined by the amount of the SSZ material flowing back to AS and the interaction between SSZ material and TMAZ material.

II. The PSZ shows typical "onion ring” structure except for the part adjacent to SSZ, where the onion rings become ambiguous, indicating a turbulent flow pattern.

III. During FSW, a certain amount of TMAZ material is dragged into the pin hole under the effect of the rotating tool. Here, the quantity of TMAZ material is determined by the area of TMAZ grains within the pin profile.

Based on the material flow patterns in different zones of the joints, a material flow model of FSW is proposed, as shown in Fig. 5. During the welding process, the upper region of the pin-sheared material tends to be extruded into the concave area of the shoulder [28]. This material, together with the shoulder-sheared material, flows around the RS with the shoulder and fills the hole at the rear of welding tool, resulting in the formation of SSZ. The pinsheared material that is not extruded into the concave part of the shoulder flows around the pin and fills the remaining hole behind the tool, which produces the PSZ.

Despite the existence of tool tilt, the shoulder still rotates in a nearly horizontal direction during FSW. The height of the SSZ material that flows horizontally reflects 


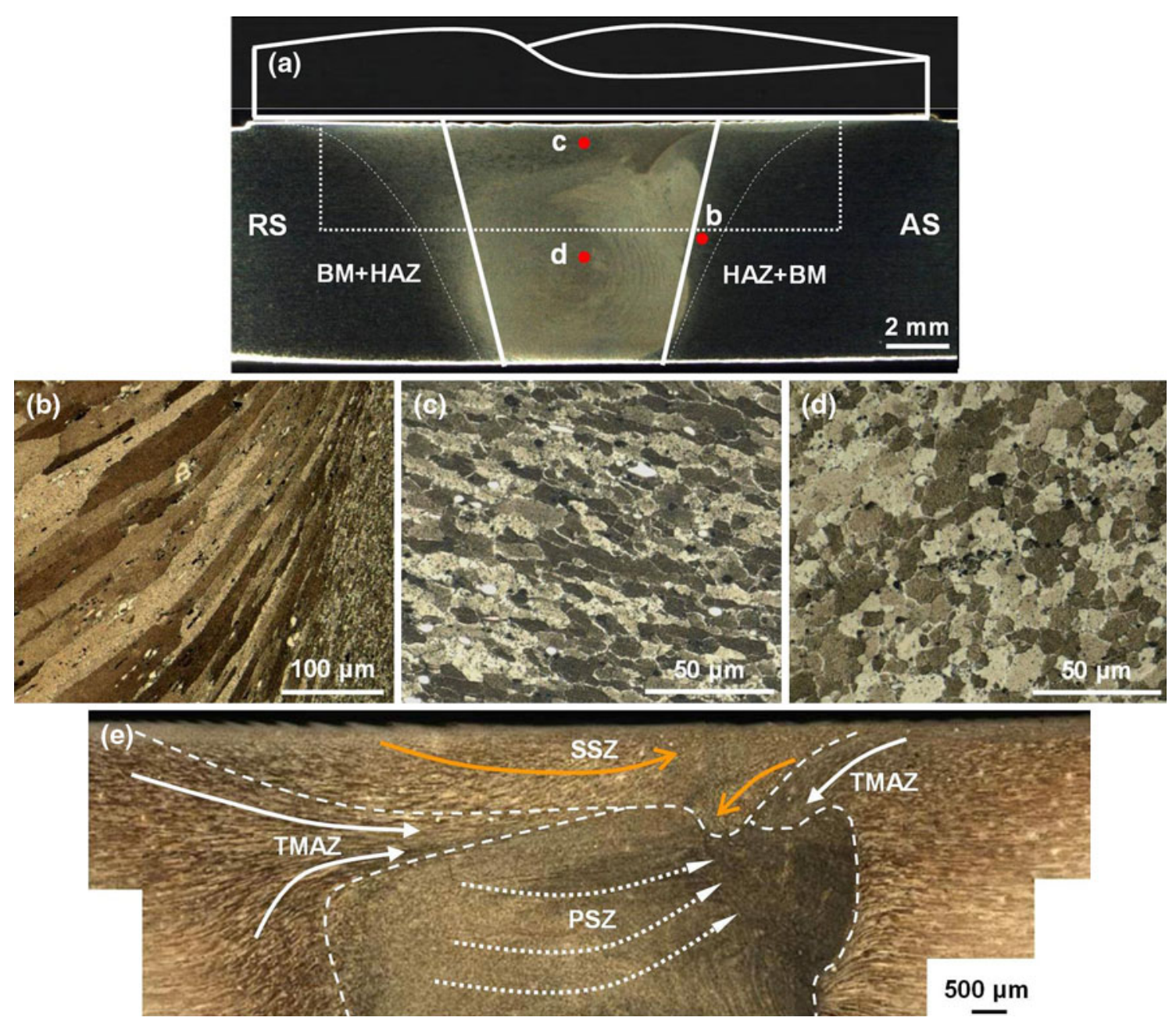

Fig. 4 Cross section and microstructures of the deformed zones of a typical underwater joint. a Cross section b TMAZ, c SSZ, d PSZ, e enlarged view of the microstructures in the dash square of Fig. 4(a)

the stirring effect of shoulder on the work piece in the thickness direction (i.e., the level of shoulder-driven flow). This height is defined as $h_{1}$ in this manuscript.

In the PSZ, the material experiences two flow patterns. One is the circle flow around tool pin, and the other is the upward flow due to the shearing of pin threads. The minimum height of the PSZ adjacent to SSZ, defined as $h_{2}$, reflects the effect of pin-driven flow on the filling of pin hole.

Influence of Process Parameters on Material Flow Patterns

\section{Influence of Rotation Speed}

Figure 6 shows cross-sectional micrographs and corresponding flow patterns for welds with a constant welding speed of $100 \mathrm{~mm} / \mathrm{min}$ and different rotation speeds. As the rotation speed increases, $h_{1}$ is significantly increased but $h_{2}$ is gradually decreased (Fig. 6a, c, e). This suggests an improvement in the stirring effect of shoulder and an enhancement of the upward flow of pin-sheared material. Additionally, the extruding reflux of SSZ material is increased on the AS with an increase in the rotation speed (Fig. 6b, d, f). When the rotation speed is increased up to $1400 \mathrm{rpm}$, turbulent material flow occurs in the PSZ adjacent to SSZ, and a void defect is observed at this location (Fig. 3c).

Weld cross sections and corresponding material flow patterns for the conditions of a relatively high constant weld speed of $200 \mathrm{~mm} / \mathrm{min}$ and varying rotation speeds are shown in Fig. 7. With increasing the rotation speed, $h_{2}$ gradually decreases, but in contrast, slight variations occur in $h_{1}$ (Fig. 7a, c, e). Furthermore, the amount of TMAZ material dragged into the pin hole increases with increasing rotation speed. At 1200 and $1400 \mathrm{rpm}$, the SSZ material flows into the pin hole in a downward direction, and welding defects such as voids and grooves are present in the joints. Prior to the occurrence of groove defect, the 
Fig. 5 Material plastic flow model for the underwater FSW. a Movement of plastic material during FSW, b material flow patterns in the deformed zones of the joint (a)

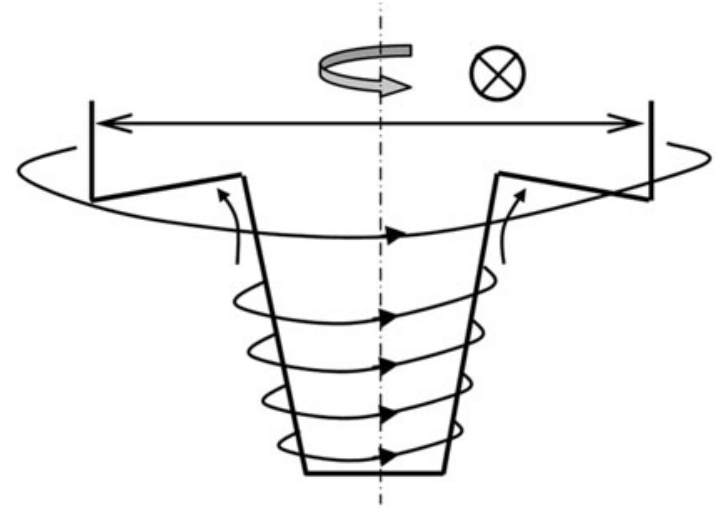

(b)

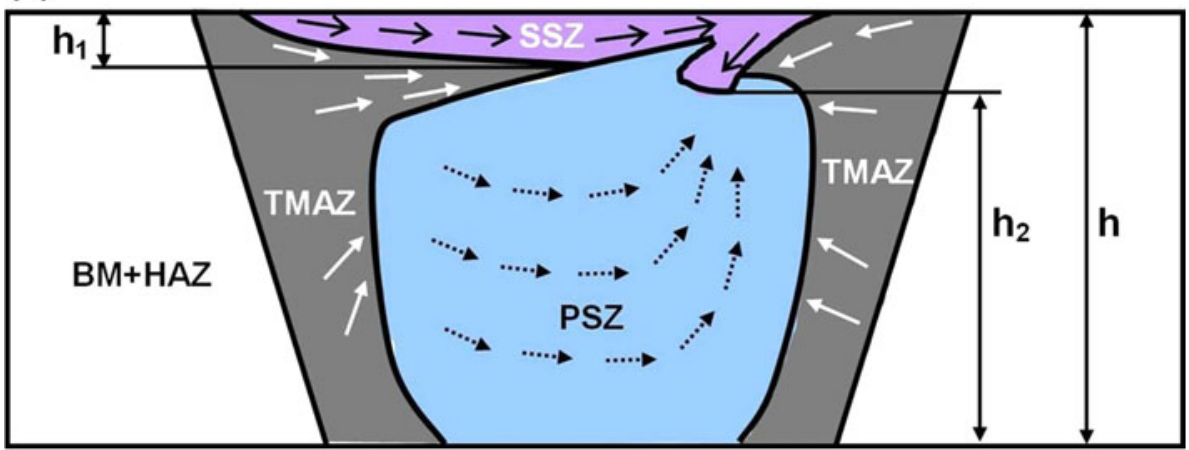

extruding reflux of SSZ material increases with increasing rotation speed (Fig. 7b, d).

\section{Influence of Welding Speed}

Figure 8 shows the cross sections and material flow patterns of welds produced at different welding speeds and a constant rotation speed of $1000 \mathrm{rpm}$. With increasing weld speed, $h_{1}$ and $h_{2}$ exhibit little variation from 100 to $200 \mathrm{~mm} / \mathrm{min}$ but decrease at $300 \mathrm{~mm} / \mathrm{min}$ (Fig. 8a, c, e). This implies that increasing the welding speed not only weakens the stirring effect of the shoulder but also enhances the upward flow of pin-sheared material. Extruding reflux of SSZ material occurs at $100 \mathrm{~mm} / \mathrm{min}$. At $200 \mathrm{~mm} / \mathrm{min}$, this phenomenon becomes more severe, leading to the turbulent flow in the PSZ; simultaneously, a certain quantity of TMAZ material is dragged into the pin hole (Fig. 8c, d). At the higher rotation speed of $300 \mathrm{~mm} / \mathrm{min}$, more TMAZ material is involved in the filling process of pin hole. When this part of TMAZ material stops flowing, SSZ material then flows into the pin hole in a downward direction, and in this case, a void defect is observed in the joint (Fig. 8e, f).

Figure 9 shows cross sections and material flow patterns of the welds produced at different welding speeds and a constant rotation speed of $1200 \mathrm{rpm} . h_{1}$ is greatly decreased when the rotation speed increases from $100 \mathrm{~mm} / \mathrm{min}$ to the range of $200-250 \mathrm{~mm} / \mathrm{min}$; additionally, $h_{2}$ also decreases progressively with increasing welding speed (Fig. 9a, c, e). At $200 \mathrm{~mm} / \mathrm{min}$, a large amount of TMAZ material is involved in filling the pin hole (Fig. 9c). Similar to the observations for Fig. 8(f), the SSZ material flows into the pin hole in a downward direction, and a void defect is formed at the PSZ adjacent to SSZ (Fig. 9d). At a higher welding speed of $250 \mathrm{~mm} / \mathrm{min}$, more TMAZ material is dragged into the pin hole, and the SSZ material exhibits greater tendency for downward flow (see Fig. 9e, f). A groove defect is formed in the joint under these conditions.

\section{Formation Mechanisms of Underwater FSW Defects}

The previously discussed observations indicate that the influence of process parameters on material flow patterns is mainly dependent on four aspects:

I. The stirring effect of shoulder on work piece, which is characterized by $h_{1}$.

II. The height of pin hole filled by PSZ material, which is characterized by $h_{2}$.

III. The amount of the extruding reflux of SSZ material.

IV. The amount of the TMAZ material that is dragged into pin hole.

At any constant rotation speed between 1000 and $1400 \mathrm{rpm}, h_{1}$ decreases with increasing welding speed, 


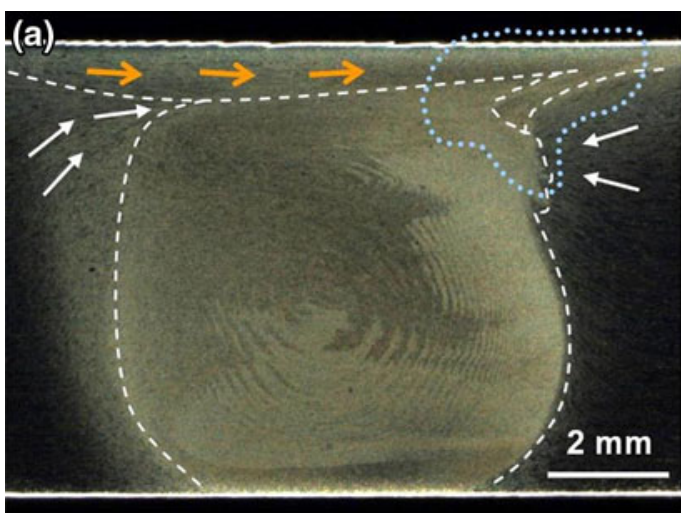

(b)
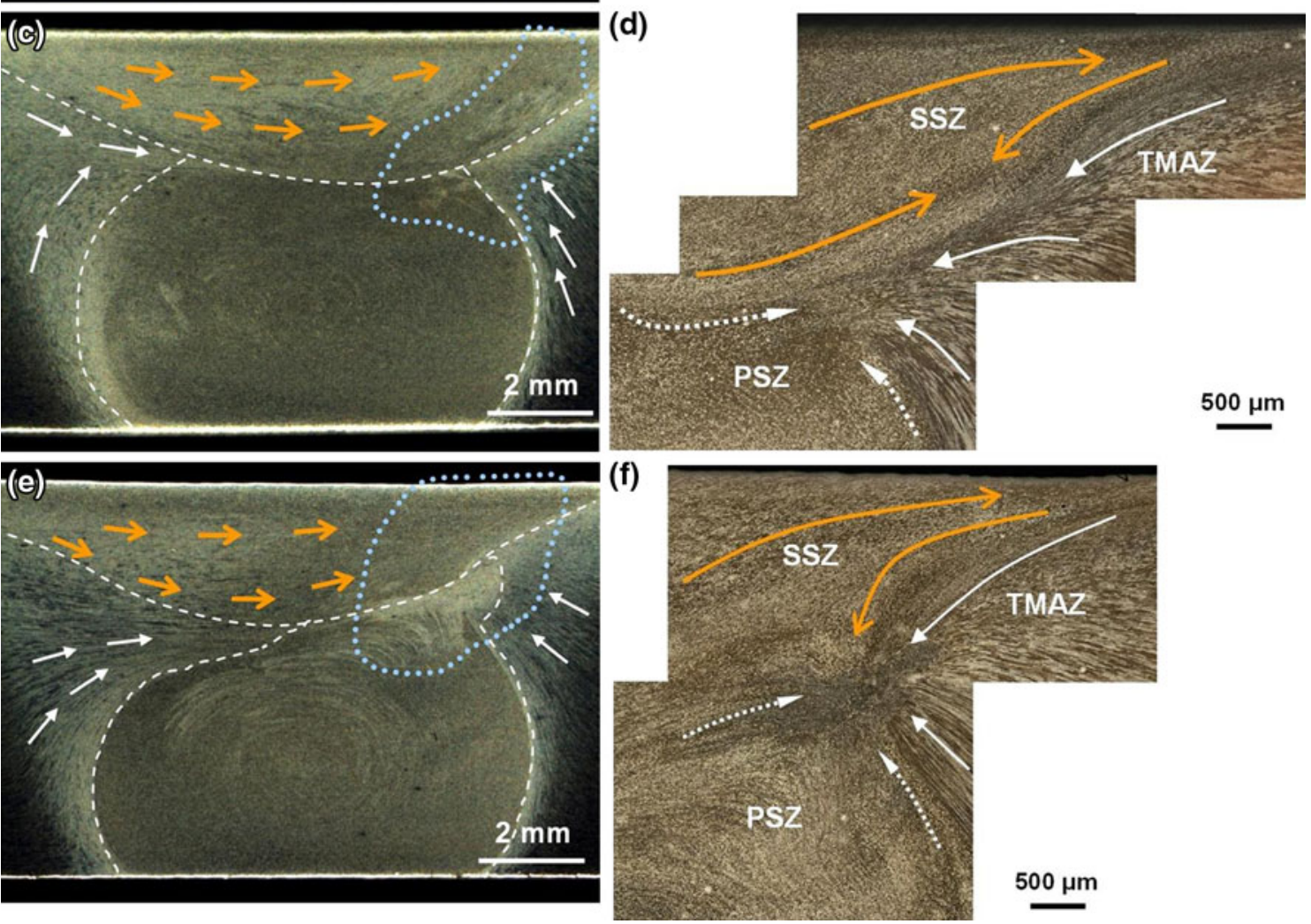

Fig. 6 Cross sections and material flow patterns of the joints obtained at different rotation speeds and constant welding speed of $100 \mathrm{~mm} / \mathrm{min}$. a, c, and e Cross sections obtained at 1000, 1200, and $1400 \mathrm{rpm}$, respectively; b, d, and $\mathbf{f}$ material flow patterns corresponding to (a), (c), and (e)

indicating that the increase of welding speed weakens the stirring effect of shoulder. This can be further verified from the evolution of $h_{1}$ with rotation speed. At a relatively low welding speed $(100 \mathrm{~mm} / \mathrm{min}), h_{1}$ is increased significantly with increasing rotation speed, but when the welding speed is fixed at a high value $(200 \mathrm{~mm} / \mathrm{min}), h_{1}$ is small for all rotation speeds and varies only slightly with rotation speed. At higher welding speeds, the time for shoulder stirring per unit length of base material is also short, which should contribute to the low value of $h_{1}$.

It is known that increasing the rotation speed can increase the fluidity of the material (i.e., reduce the material flow stress due to increased heat input), while increasing the welding speed improves the extrusion force between tool pin and base material. Therefore, increasing the rotation speed at a fixed welding speed or increasing the welding speed at a fixed rotation speed both exert a positive effect on the upward flow of pin-sheared material, and thus results in a decrease of $h_{2}$.

The increase of rotation speed or welding speed both enhance the interaction between SSZ material and TMAZ material. For this reason, the amount of extruding reflux of SSZ material is increased with increasing rotation speed. However, it does not show a specific evolving tendency with the welding speed. This is attributed to the gradual 

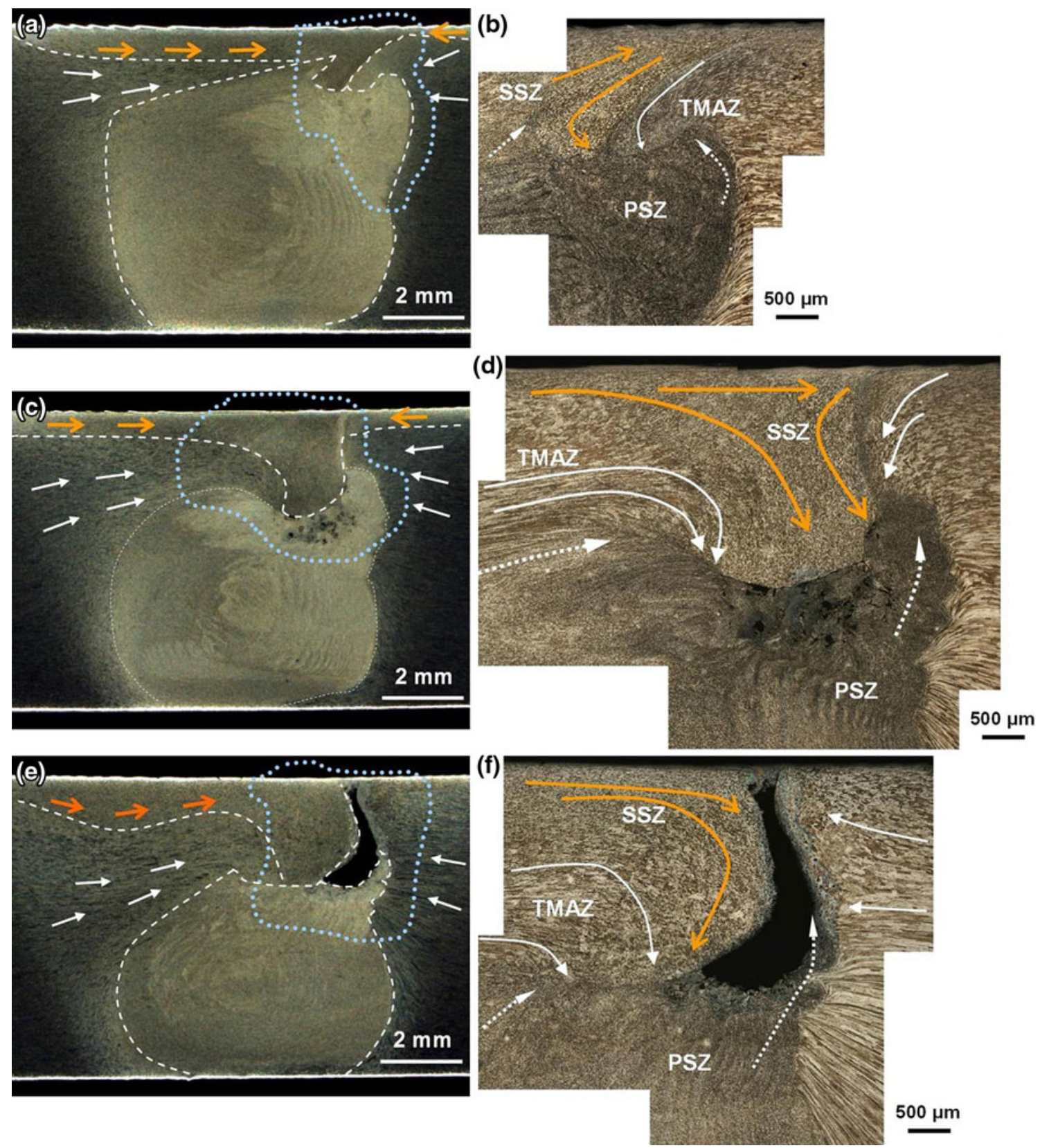

Fig. 7 Cross sections and material flow patterns of the joints obtained at different rotation speeds and constant welding speed of $200 \mathrm{~mm} / \mathrm{min}$. a, c, and e Cross sections obtained at 1000, 1200, and $1400 \mathrm{rpm}$, respectively; b, d, and $\mathbf{f}$ material flow patterns corresponding to (a), (c), and (e)

reduction of the SSZ material that flows back to AS when the welding speed is increased.

The amount of the TMAZ material involved in the filling process of pin hole is dependent on the sum of $h_{1}$ and $h_{2}$. If the height of the pin hole filled by PSZ material is small, and the shoulder has a weak stirring effect on the work piece, a large amount of TMAZ material is then dragged into the pin hole by the viscous force of SZ material.

Figure 10 presents a quantitative analysis of $h_{1}, h_{2}$ and the extruding reflux of SSZ material obtained at relatively
HRS. The welds with HRS defects are classified into two types according to their formation characteristics: a large sum of $h_{1}$ and $h_{2}$, or a small sum of $h_{1}$ and $h_{2}$. Further analysis finds that welds with a large $h_{1}$ and $h_{2}$ sum are a result of a low welding speed $(100 \mathrm{~mm} / \mathrm{min})$, while the low sum type is a result of a relatively high welding speed (200-300 $\mathrm{mm} / \mathrm{min})$. Both the types of welds are characterized by different material flow patterns, as described in section 3. Therefore, it can be concluded that the formation mechanism of HRS defects is dependent on the welding speed. In other words, HRS defects can be divided into two 


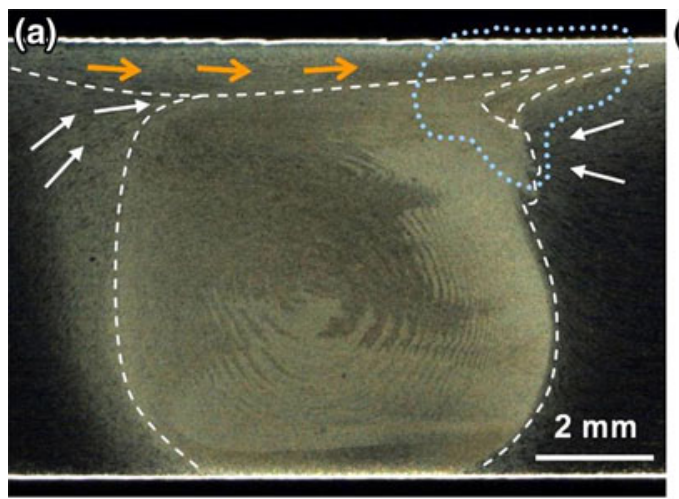

(b)
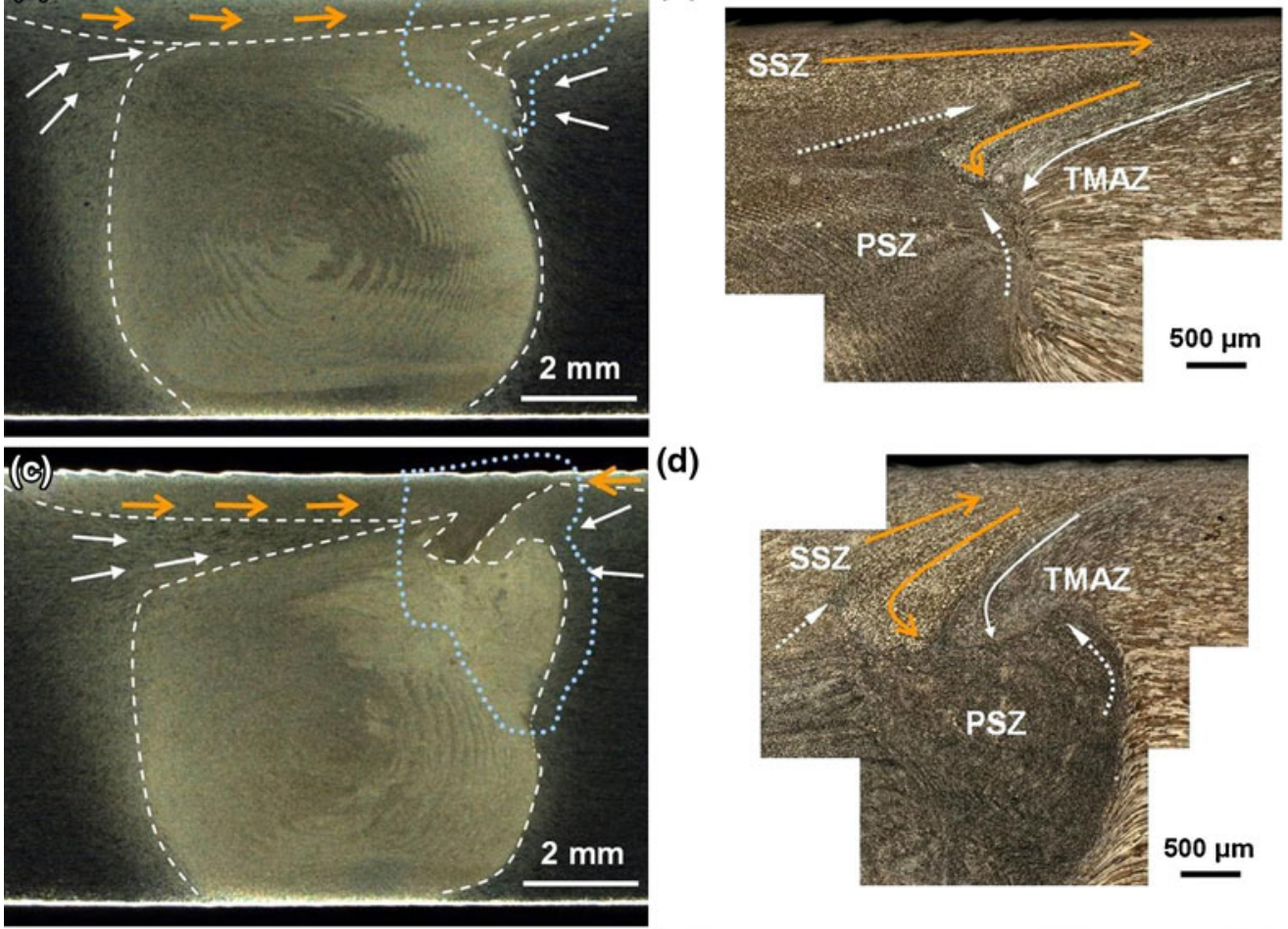

(d)
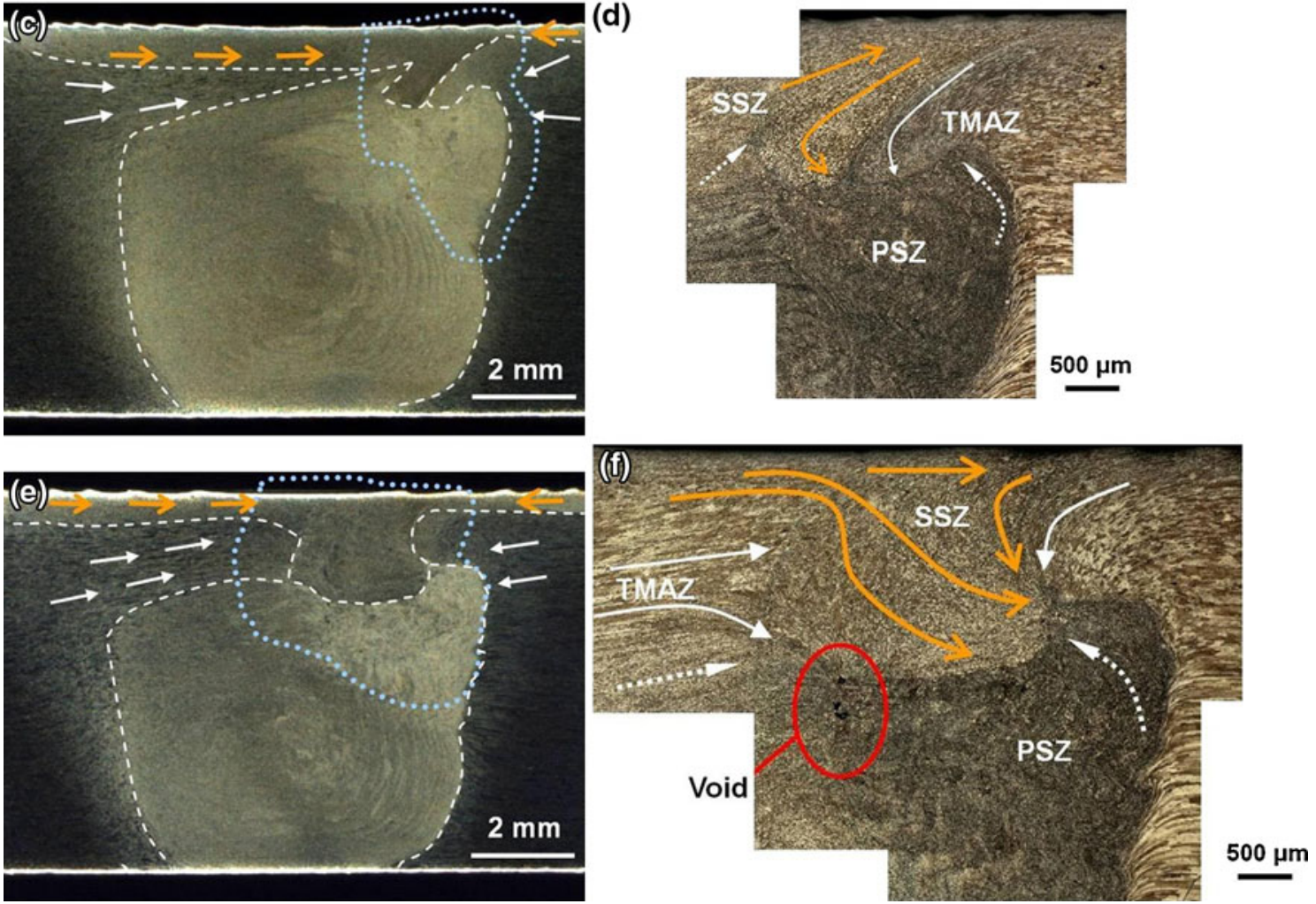

Fig. 8 Cross sections and material flow patterns of the joints obtained at different welding speeds and constant rotation speed of $1000 \mathrm{rpm}$. a, c, and e Cross sections obtained at 100, 200, and $300 \mathrm{~mm} / \mathrm{min}$, respectively; b, d, and $\mathbf{f}$ material flow patterns corresponding to (a), (c), and (e)

types, i.e., defects formed at low welding speeds and defects formed at high welding speeds. In the low speed case, $h_{1}$ is large and the sum of $h_{1}$ and $h_{2}$ is comparable to the weld thickness, $h$. For the high speed case, $h_{1}$ is rather small and the sum of $h_{1}$ and $h_{2}$ is significantly lower than the weld thickness. Based on the evolution of material flow patterns with process parameters, the formation mechanisms of these two types of defects are separately discussed.

At a HRS of $1400 \mathrm{rpm}$ and a relatively low welding speed of $100 \mathrm{~mm} / \mathrm{min}$, the shoulder exerts severe stirring effect on the work piece, making the sum of $h_{1}$ and $h_{2}$ comparable to weld thickness $h$. Under this condition, the shoulder- and pin-driven flows are consistent in direction near the SSZ/PSZ interface. However, a large amount of SSZ material is transferred back to the AS from the RS during FSW. This increases the extrusion force between SSZ and TMAZ materials, leading to more extruding reflux of SSZ material and thus the turbulent flow in the PSZ. Consequently, a void defect is formed in the PSZ adjacent to SSZ (Fig. 3c). That is to say, the larger amount of extruding reflux of SSZ material is responsible for the formation of HRS defect, and this viewpoint is in agreement with Arbegast's results [21].

When relatively high welding speeds $(200-300 \mathrm{~mm} / \mathrm{min})$ are combined with HRS, the shoulder stirring effect is dramatically weakened and the height of the pin hole filled by PSZ material is also small. Under this condition, a large 

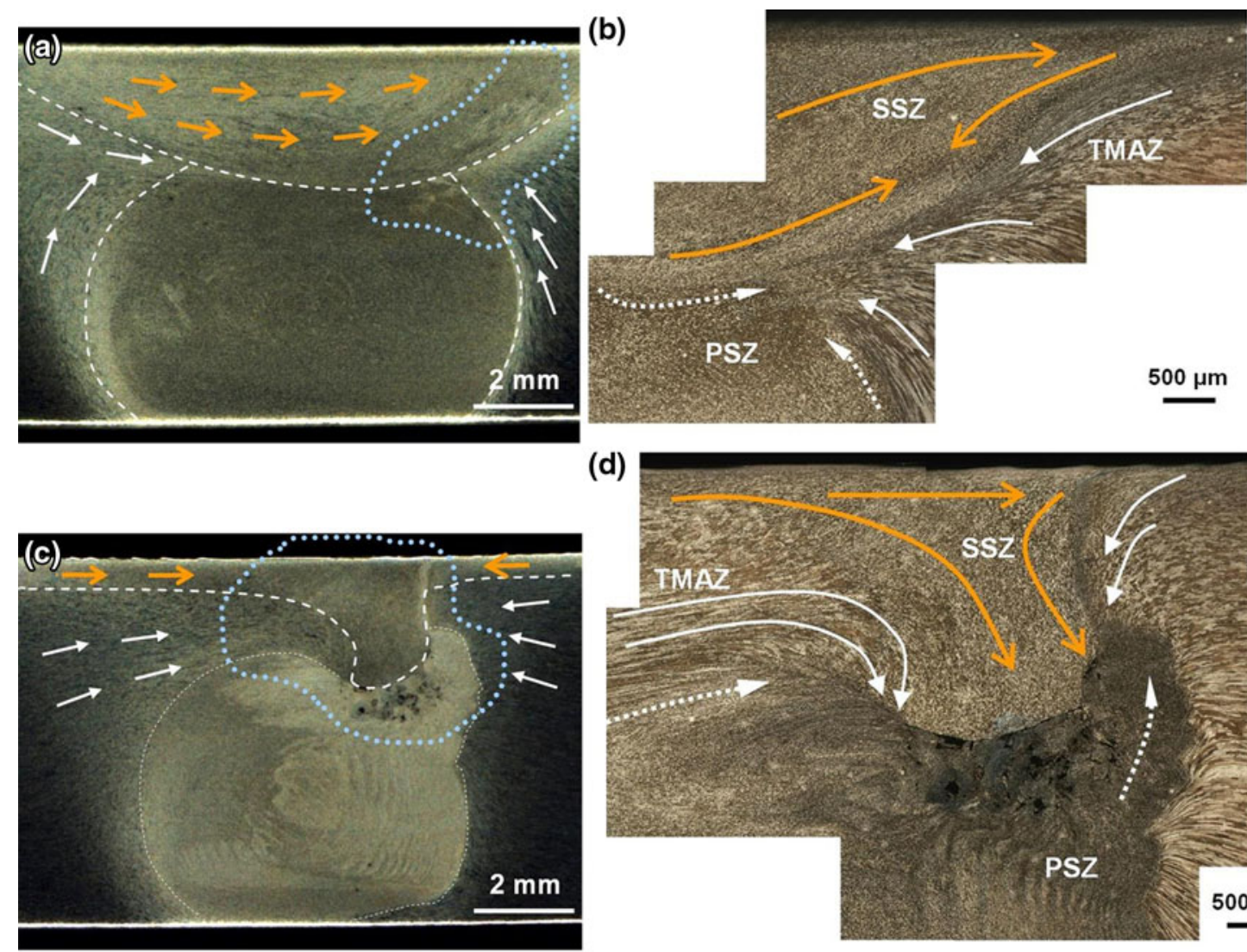

(d)

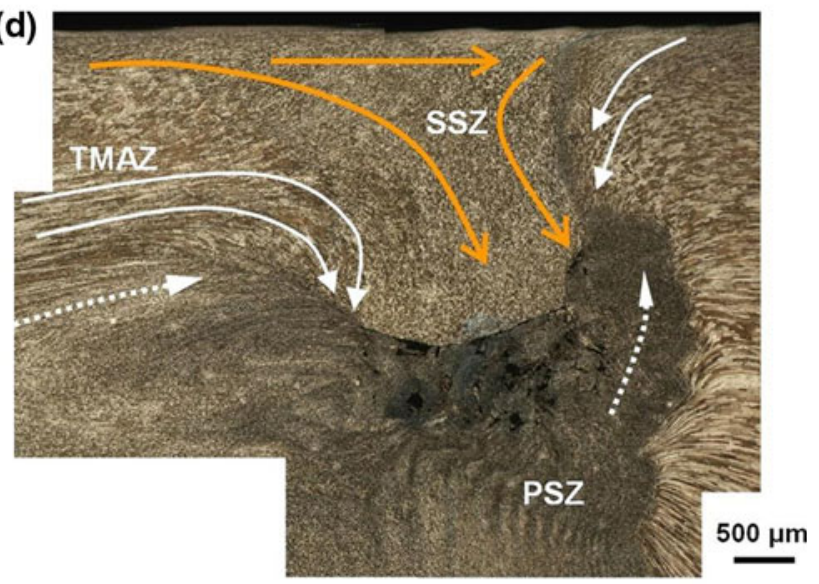

(f)
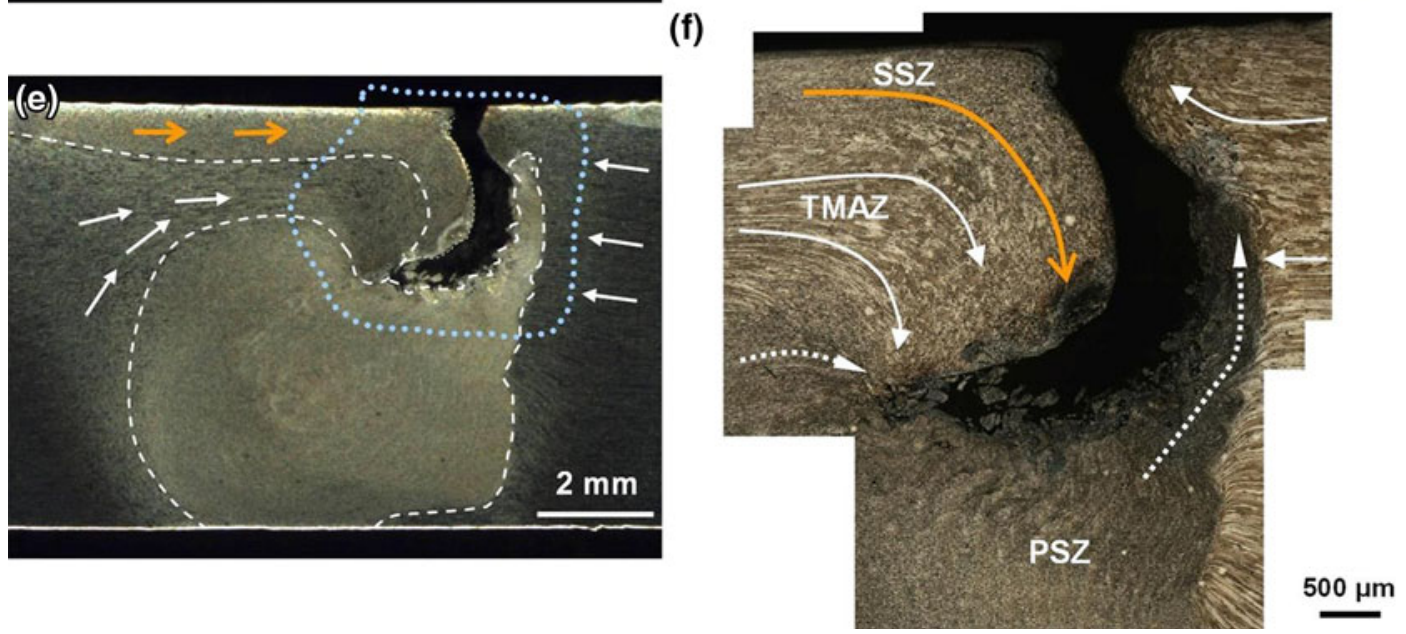

Fig. 9 Cross sections and material flow patterns of the joints obtained at different welding speeds and constant rotation speed of $1200 \mathrm{rpm}$. a, c, and e Cross sections obtained at 100, 200, and $250 \mathrm{~mm} / \mathrm{min}$, respectively; b, d, and $\mathbf{f}$ material flow patterns corresponding to (a), (c), and (e)

amount of TMAZ material tends to be dragged into the pin hole by the viscous force of SZ material (Fig. 11a-d). The TMAZ material possesses lower fluidity than SSZ material; when it stops flowing, the SSZ material then fills the remaining pin hole in a downward flow direction (Fig. 11ef). This disturbs the regular flow of the PSZ material and causes a turbulent flow in PSZ. The resultant strain/strain rate gradients then lead to the microstructure discontinuities according to mass balance principle, and finally void defects occur in the joints (Figs. 8f, 9d). Although extruding reflux of SSZ material is also observed in this case, it exerts little effect on the void formation, which can be confirmed by the exact locations of void defects. If the rotation speed is rather high, $h_{2}$ is then further decreased, making the downward flow of SSZ material more severe. For this reason, the amount of SSZ material that flows back to the AS is insufficient, which leads to the occurrence of a groove defect (Figs. 7f, 9f). 
Fig. $10 h_{1}, h_{2}$, and extruding reflux obtained at different process parameters

Fig. 11 Schematic view of the formation mechanism of HRS defect. a, c, e Horizontal plane of the weld; $\mathbf{b}, \mathbf{d}, \mathbf{f}$ cross sections of the weld (made along the red lines in $\mathbf{a}, \mathbf{c}$, and $\mathbf{e})$
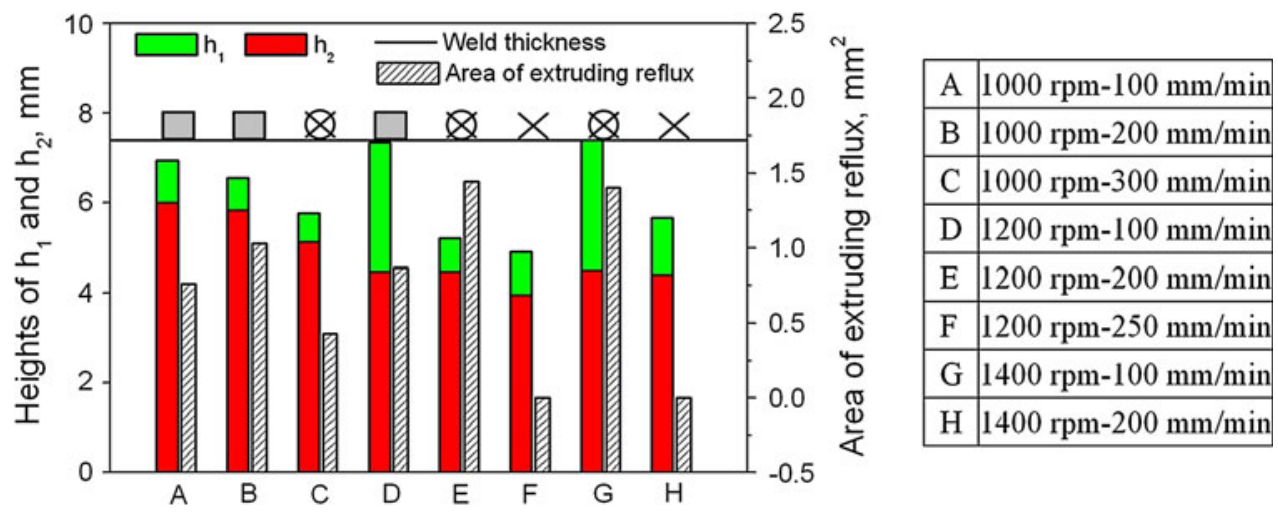

(b)
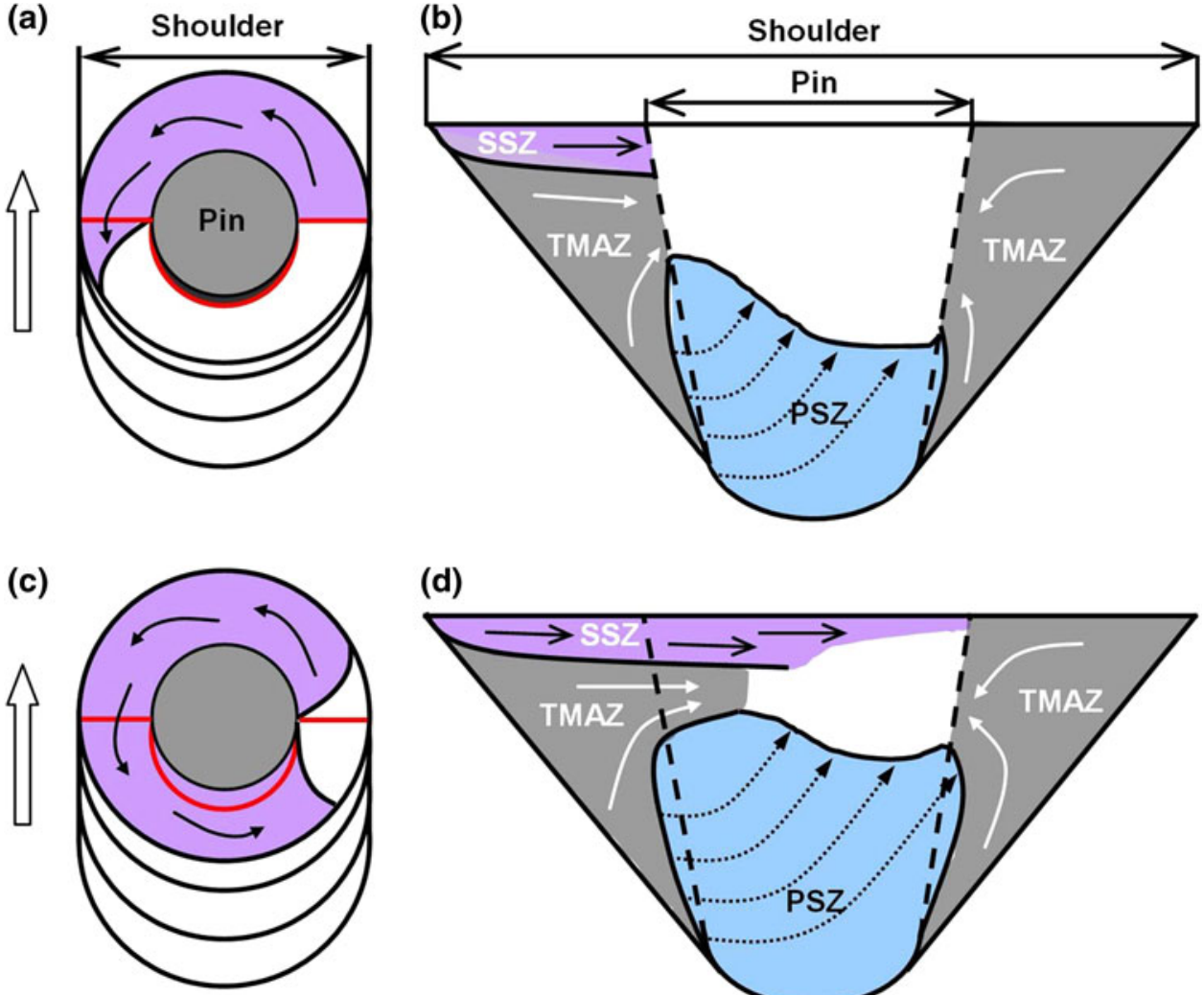

(d)
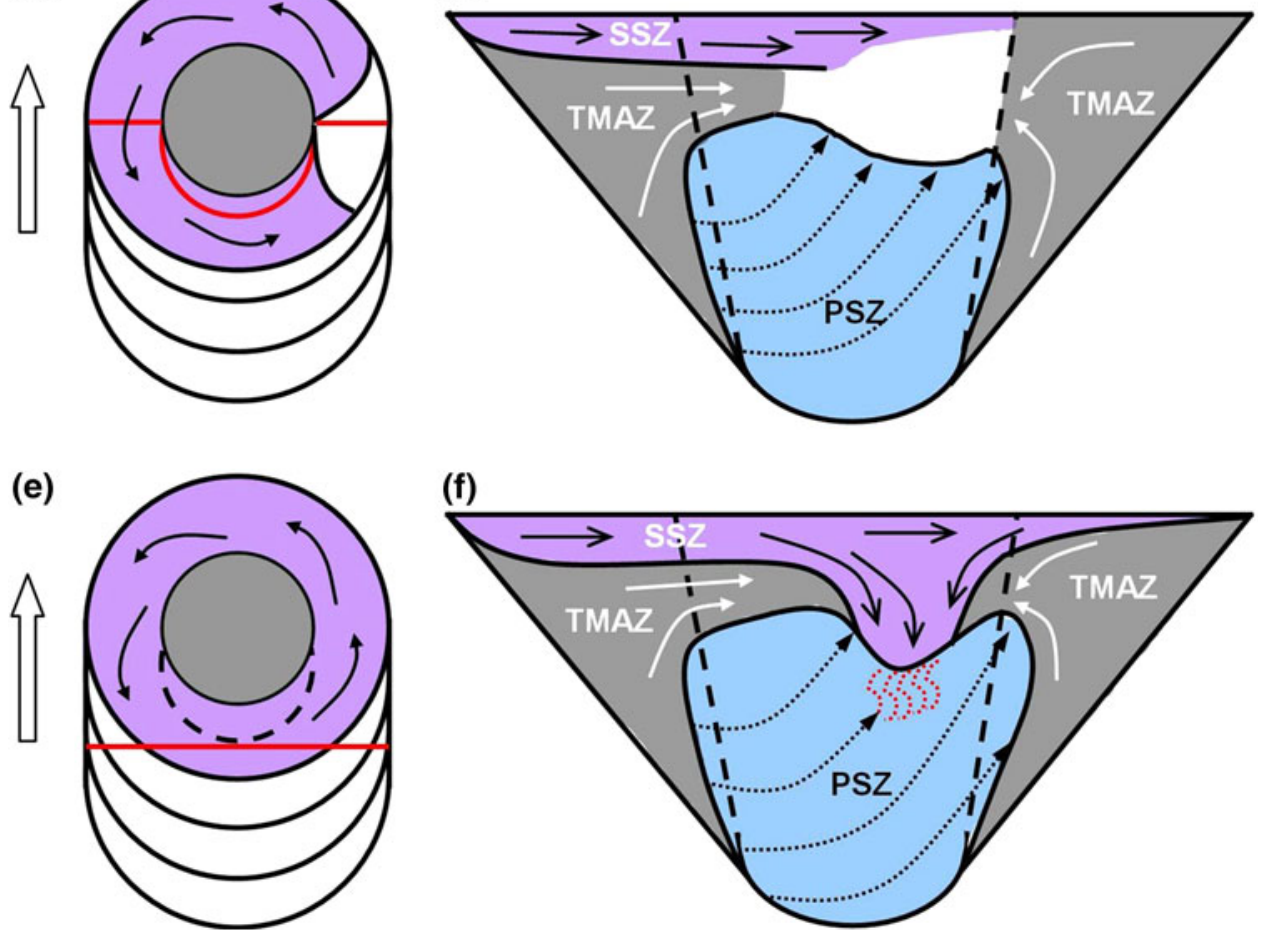

(f)

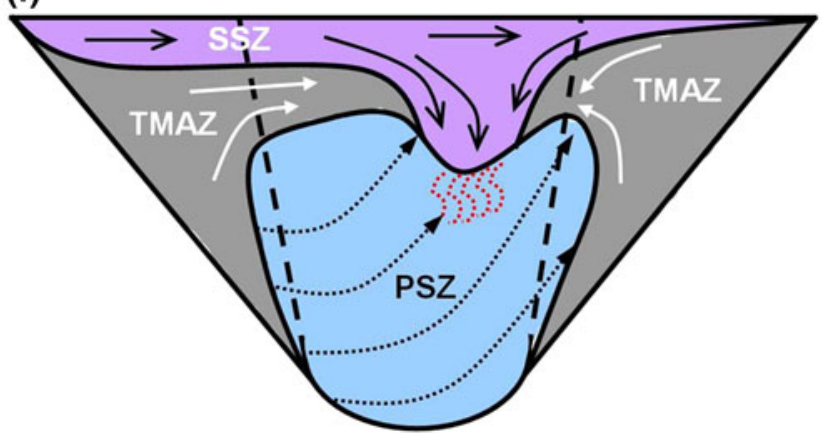

welding speeds; second, it promotes the upward flow of pinsheared material. The high welding speed also plays two roles. Besides the promotion of upward flow of pin-sheared
HRS serves two functions. First, it provides the material sufficient plasticity and fluidity even at relatively high 
material, it dramatically weakens the stirring effect of shoulder on the work piece. Therefore, if a higher welding speed is chosen, the rotation speed should be low to retard the upward flow of pin-sheared material. On the contrary, if a higher rotation speed is utilized, the welding speed should be low to improve the stirring effect of shoulder on the work piece. These are the reasons why HRS coupled with low welding speed, or LRS coupled with high welding speed, generally produce defect-free underwater joints.

Previous investigations also observed the occurrence of HRS defects during FSW of aluminum alloys, and some researchers have attempted to elucidate the formation mechanisms of HRS defects [20, 21, 23]. However, these previously published studies mainly focused on the effect of HRS, and the effect of welding speed was rarely mentioned. Although Kim et al. [20] found that increasing the welding speed increased the size of HRS defects, the reason for this was not deeply investigated in their research. By analyzing the defect characteristics and material flow patterns in underwater FSW, this work for the first time proposes a relationship between the formation mechanism of HRS defects and welding speed. When the welding speed is low, the formation mechanism of HRS defect is found to be the same as that reported by previous researchers [21], as described above. However, at relatively high welding speed, the formation mechanism of HRS defect is quite different. In this case, a large amount of TMAZ material tends to be dragged into the pin hole, which causes the significant downward flow of SSZ material and finally the occurrence of HRS defects.

\section{Conclusions}

1. LRS and HRS can both yield welding defects during underwater FSW. The LRS defect is generally found at the SZ/TMAZ interface on the AS, while the HRS defect tends to be present in the SZ. When the rotation speed is increased, the LRS defect becomes small and may even be eliminated, but the size of HRS defect gradually increases.

2. The insufficient heat input and lower fluidity of material are reasons for the formation of LRS defect. The HRS defect can be divided into two types according to the welding speed.

3. The HRS defect formed at low welding speed is induced by the larger extent of extruding reflux of SSZ material on the AS.

4. At HRS and high welding speed, a large amount of TMAZ material is dragged into the pin hole, which causes the SSZ material to flow into the pin hole in a downward direction. This not only leads to turbulent flow in PSZ, but also reduces the amount of SSZ material that flows back to AS. Finally, void and even groove defects are formed in the joints.

Acknowledgments The authors are grateful to be supported by the National Basic Research Program of China (973 Program, 2010CB731704), National Natural Science Foundation of China (51175117) and the National Science and Technology Major Project of China (2010ZX04007).

\section{References}

1. W.M. Thomas, E.D. Nicholas, J.C. Needham, M.G. Murch, P. Temple-Smith, C.J. Dawes, Friction Stir Butt Welding, International Patent Application No. PCT/GB92/02203 and GB Patent Application No. 9125978.8; 1991

2. M.R. Johnsen, Friction stir welding takes off at boeing. Weld. J. 78, 35-39 (1999)

3. D. Joelj, The friction stir welding advantage. Weld. J. 80, 30-34 (2001)

4. R.S. Mishra, Z.Y. Ma, Friction stir welding and processing. Mater. Sci. Eng. Rep. 50, 1-78 (2005)

5. P.L. Threadgill, A.J. Leonard, H.R. Shercliff, P.J. Withers, Friction stir welding of aluminum alloys. Int. Mater. Rev. 54, 49-93 (2009)

6. M.W. Mahoney, C.G. Rhodes, J.G. Flintoff, R.A. Spurling, W.H. Bingel, Properties of friction-stir-welded 7075 T651 aluminum. Metall. Mater. Trans. A 29, 1955-1964 (1998)

7. Y.S. Sato, H. Kokawa, M. Enomoto, S. Jogan, Microstructural evolution of 6063 aluminum during friction-stir welding. Metall. Mater. Trans. A 30, 2429-2437 (1999)

8. R.W. Fonda, J.F. Bingert, Microstructural evolution in the heataffected zone of a friction stir weld. Metall. Mater. Trans. A 35, 1487-1499 (2004)

9. F.C. Liu, Z.Y. Ma, Influence of tool dimension and welding parameters on microstructure and mechanical properties of friction-stir-welded 6061-T651 aluminum alloy. Metall. Mater. Trans. A 39, 2378-2388 (2008)

10. S. Benavides, Y. Li, L.E. Murr, D. Brown, J.C. McClure, Lowtemperature friction-stir welding of 2024 aluminum. Scripta Mater. 41, 809-815 (1999)

11. L. Fratini, G. Buffa, R. Shivpuri, In-process heat treatments to improve FS-welded butt joints. Int. J. Adv. Manuf. Technol. 43, 664-670 (2009)

12. L. Fratini, G. Buffa, R. Shivpuri, Mechanical and metallurgical effects of in process cooling during friction stir welding of AA7075-T6 butt joints. Acta Mater. 58, 2056-2067 (2010)

13. H.J. Liu, H.J. Zhang, Y.X. Huang, L. Yu, Mechanical properties of underwater friction stir welded 2219 aluminum alloy. Trans. Nonferrous Met. Soc. China 20, 1387-1391 (2010)

14. H.J. Liu, H.J. Zhang, L. Yu, Homogeneity of mechanical properties of underwater friction stir welded 2219-T6 aluminum alloy. JMEPEG 20, 1419-1422 (2011)

15. H.J. Zhang, H.J. Liu, L. Yu, Microstructure and mechanical properties as a function of rotation speed in underwater friction stir welded aluminum alloy joints. Mater. Des. 32, 4402-4407 (2011)

16. H.J. Liu, H. Fujii, M. Maeda, K. Nogi, Tensile properties and fracture locations of friction-stir-welded joints of 2017-T351 aluminum alloy. J. Mater. Process. Technol. 142, 692-696 (2003)

17. Y.C. Chen, H.J. Liu, J.C. Feng, Friction stir welding characteristics of different heat-treated-state 2219 aluminum alloy plates. Mater. Sci. Eng., A 420, 21-25 (2006)

18. L. Cui, X.Q. Yang, G. Zhou, X.D. Xu, Z.K. Shen, Characteristics of defects and tensile behaviors on friction stir welded AA6061T4 T-joints. Mater. Sci. Eng., A 543, 58-68 (2012) 
19. A.J. Leonard, S.A. Lockyer, Flaws in friction stir welds, Proceedings of the 4th International Symposium on Friction Stir Welding, Paper No. S2-P1, Utah, USA. TWI Ltd., May, 2003

20. Y.G. Kim, H. Fujii, T. Tsumura, T. Komazaki, K. Nakata, Three defect types in friction stir welding of aluminum die casting alloy. Mater. Sci. Eng., A 415, 250-254 (2006)

21. W.J. Arbegast, A flow-partitioned deformation zone model for defect formation during friction stir welding. Scripta Mater. 58, 372-376 (2008)

22. B. Li, Y.F. Shen, W.Y. Hu, The study on defects in aluminum 2219-T6 thick butt friction stir welds with the application of multiple non-destructive testing methods. Mater. Des. 32, 2073-2084 (2011)

23. A.M. Gaafer, T.S. Mahmoud, E.H. Mansour, Microstructural and mechanical characteristics of AA7020-O Al plates joined by friction stir welding. Mater. Sci. Eng., A 527, 7424-7429 (2010)
24. P.B. Prangnell, C.P. Heason, Grain structure formation during friction stir welding observed by the "Stop Action Technique". Acta Mater. 53, 3179-3192 (2005)

25. R.M. Leal, C. Leitão, A. Loureiro, D.M. Rodrigues, P. Vilaca, Material flow in heterogeneous friction stir welding of thin aluminium sheets: effect of shoulder geometry. Mater. Sci. Eng., A 498, 384-391 (2008)

26. Z.W. Chen, T. Pasang, Y. Qi, Shear flow and formation of nugget zone during friction stir welding of aluminium alloy 5083-O. Mater. Sci. Eng., A 474, 312-316 (2008)

27. S.M. Chowdhury, D.L. Chen, S.D. Bhole, X. Cao, Tensile properties of a friction stir welded magnesium alloy: effect of pin tool thread orientation and weld pitch. Mater. Sci. Eng., A 527, 6064-6075 (2010)

28. K. Kumar, S.V. Kailas, The role of friction stir welding tool on material flow and weld formation. Mater. Sci. Eng., A 485, 367-374 (2008) 